\title{
Padre Cícero: o ocaso de uma condenação
}

\section{Entrevista com Annette Dumoulin"}

\author{
Edimar Brígido**
}

Annette Dumoulin nasceu em Liège, Bélgica, no ano de 1935. É mestre e doutora em Ciência da Educação, com especialização em Psicologia da Religião pela Universidade Católica de Lovaina, Bélgica. Foi professora nas faculdades de Teologia, Psicologia e Pedagogia da mesma universidade. É religiosa da Congregação de Nossa Senhora, e co-fundadora do Centro de Psicologia da Religião (CPR), que contribui com as pesquisas sobre a história e a vida de Padre Cícero. É autora das seguintes obras: O Padre Cícero por ele mesmo (2015); Em Sonho: uma Boa Conversa Entre o Romeiro Sebastião e Padre Cícero (2017); Padre Cícero: Santo dos Pobres, Santo da Igreja (2017).

\section{Primeiros passos}

É preciso revolver a terra seca do Sertão do Cariri para descobrir as marcas deixadas pelo julgamento que culminou na condenação do padre mais popular do nordeste brasileiro. Entre defesas e acusações, Juazeiro se tornou território da disputa dialógica e jurídica, conquistando importância, não somente religiosa, mas também política. $O$ chão deste ambiente é sagrado, uma vez que foi regado com o suor de milhares de homens e de mulheres que tornaram-se romeiros, peregrinos deserdados da sorte, desprovidos de amparo, em busca de solução para seus conflitos.

* Entrevista realizada no dia 15 de outubro de 2018.

** Doutor em Filosofia. Professor de Ética e Filosofia no Centro Universitário Curitiba UNICURITIBA. 
Foi bem ali, no sul do Ceará, naquele lugar pobre e esquecido por muitos, que a cidade de Crato viu nascer padre Cícero, no dia 24 de março de 1844. Filho de Joaquim Romão Batista e Joaquina Vicência Romana - conhecida como Dona Quinô -, solenemente batizado com o nome de Cícero Romão Batista. De infância humilde, teve que ajudar a mãe e as irmãs solteiras quando fatalmente perdeu o pai ${ }^{1}$, vítima de um surto de cólera que se alastrava por aquela região. O desejo de ser sacerdote teve que ser adiado por algum tempo. Os estudos no Colégio do padre Inácio de Sousa Rolim, na Paraíba, tiveram que ser abandonados, já que a situação financeira da família se agravara muito desde então ${ }^{2}$.

Anos mais tarde, graças ao auxílio financeiro que recebeu por iniciativa de seu padrinho de crisma, coronel Antônio Luiz Alves Pequeno, conseguiu ingressar no Seminário da Prainha, localizado em Fortaleza, finalmente retomando a formação acadêmica rumo à vida religiosa.

Antes disso, aos doze anos de idade, inspirado pela leitura que fez a respeito da vida e missão de São Francisco de Sales, fez seu primeiro voto de castidade, o qual seria confirmado anos mais tarde, por ocasião de sua ordenação presbiteral, celebrada em 30 de novembro de 1870 . Enquanto aguardava pela nomeação de pároco, retornou para a cidade de Crato, ocupando seus dias como professor de latim no Colégio Padre Ibiapina, fundado pelo seu primo, professor José Joaquim Teles Marrocos.

Decorrido um ano após a ordenação religiosa, em dezembro de 1871, padre Cícero foi convidado pelo professor Semeão Correa de Macedo, para celebrar a Missa de Natal na pequena capela de Nossa Senhora das Dores, em Juazeiro. O jovem padre de olhos azuis e cabelos loiros, com apenas 28 anos de idade, mal sabia que aquele primeiro encontro com o povoado de Juazeiro mudaria sua vida para sempre, propiciando dores e alegrias, condenação e redenção.

\section{Entrevista}

Irmã Annette Dumoulin, obrigado por destinar parte do seu tempo para esta conversa a respeito de uma figura tão polêmica e, ao mesmo

\footnotetext{
O pai foi um pequeno comerciante no Crato.

2 WALKER, Daniel. Pequena Biografia do Padre Cícero. Juazeiro do Norte: eBooksBrasil, 1999, p. 7-8.
} 
tempo, tão estimada pelo povo nordestino, o padre Cícero Romão Batista. Nosso objetivo é analisar mais de perto os motivos que levaram a Igreja a condená-lo, bem como a reconciliá-lo, recentemente 3 .

A senhora poderia nos falar um pouco a respeito da importância da figura de padre Cícero para o povo do Sertão do Cariri?

Annette Dumoulin - Padre Cícero é, antes de tudo, o $\underline{\text { Padrinho }}$ do povo do Sertão, não somente do Cariri! Ele entrou nas famílias como um membro importante e respeitado: ancião, conselheiro, protetor, intercessor, santo. Não se trata de um "apadrinhamento" como acontecia com os "coronéis".

Como o Padre Cícero foi rejeitado pela própria Igreja, durante dezenas de anos, sua devoção foi transmitida dentro das famílias, de pais para filhos, e se perpetua por gerações numa "catequese familial" (ver a carta do Cardeal Parolin, $n{ }^{\circ} 5$ ).

Nesse sentido, achamos que ser afilhado do Padrinho é percebido como uma valorização da identidade do afilhado, dando-lhe um sentimento de dignidade e de pertença.

Lembro-me de um fato que aconteceu há anos no Recife: um homem importante provocou um acidente de carro a uma pessoa de classe “inferior"! Claro que o responsável saiu do carro berrando contra o "pequeno condutor" e acrescentando: "você não sabe com quem esta falando". O "pequeno" escutou e respondeu calmamente: "O Senhor não sabe também com quem está falando: eu sou afilhado do Padre Cícero!"

Edimar Brígido - Mesmo sendo uma figura tão carismática, despertando a simpatia de ricos e pobres, quais foram os principais motivos que levaram a Igreja a condenar padre Cícero, após o "milagre de Juazeiro"?

Esta entrevista não seria possível sem os trabalhos técnicos de José Eduardo Laureano Soares, acadêmico do curso de Filosofia da Faculdade Vicentina. 


\section{Annette Dumoulin -}

1. Antes do fenômeno da transformação da hóstia em sangue, na boca de Maria de Araújo, (1/03/1889) os arquivos revelam a valorização desse sacerdote, não só pelos bispos de Fortaleza (Dom Luiz e Dom Joaquim), mas pelo clero que o procurava para conselhos, confissões...

2. O primeiro motivo foi o fato que dom Joaquim não tinha sido comunicado pessoalmente do fenómeno, mas por um artigo de jornal! A suposta desobediência de Maria de Araújo a uma ordem do Bispo (ir morar no Crato) confirmou para dom Joaquim que a Beata era embusteira e que o "milagre" era uma farsa.

3. Um segundo motivo foi de ordem teológica: pode ou não adorar os panos ensanguentados como sendo o próprio sangue de Cristo, segundo São Tomas de Aquino (latria-adoração ou dulia-veneração). As opiniões eram divergentes entre dom Joaquim e padre Cícero.

4. Depois de dois inquéritos contraditórios enviados na Sagrada Congregação do Santo Ofício, Roma condenou o fenómeno. Padre Cícero e outros padres que acreditavam no milagre foram suspensos de ordem.

5. Vendo que a quantidade de romeiros não diminuía, o Bispo considerou que era preciso que Padre Cícero saísse de Juazeiro. Comunicou essa opinião a Roma. Padre Cícero teve que sair sob pena de excomunhão. Ele foi para Salgueiro (Pernambuco) e pegou o navio para Roma. Voltou de Roma "perdoado", com a promessa de guardar um "silêncio obsequioso" sobre o fenómeno. O que ele fez.

6. O Bispo ficou insatisfeito e só devolveu a padre Cícero a licença de celebrar fora de Juazeiro... tudo isso na tentativa de ver diminuir a afluência dos romeiros.

7. Quando se criou a diocese do Crato, o novo Bispo, dom Quintino, devolveu essa licença e Padre Cícero voltou a celebrar no Juazeiro; mas, por pouco tempo.

8. A "Guerra de 14" entre Franco Rabelo e Juazeiro reativou as condenações vindas de Roma. O terceiro Bispo de Fortaleza, dom Manuel, mandou mensagens ao Núncio que o Padre estava 
matando cristãos! Roma mandou um decreto de excomunhão, mas o Bispo, dom Quintino não aplicou a sentença e pediu ao Papa de retirar essa punição e devolver ao Padre a licença de celebrar. Roma atendeu parcialmente. A excomunhão foi revogada, mas o Padre foi "reduzido ao estado leigo". É nessa situação que ele faleceu, recebendo os sacramentos como "leigo".

Edimar Brígido - Por que a condenação não foi suficiente para dispersar as peregrinações recorrentes que começavam a se formar em torno de padre Cícero?

Annette Dumoulin - Porque os romeiros consideraram que Padre Cícero era perseguido injustamente pelas autoridades eclesiais. Eles se identificaram a ele, pois eles, também, eram perseguidos injustamente. Criou-se, então, uma fidelidade profunda entre o povo sofrido e o Padre perseguido. Essa fidelidade foi recíproca e continua até hoje.

Edimar Brígido - Entre outras polêmicas envolvendo o padre, podemos lembrar da relação intensa que ele manteve com a política, chegando, inclusive, a ocupar o cargo de vice-presidente do Ceará. O ministério sacerdotal de padre Cícero não era incompatível com as articulações políticas?

Annette Dumoulin - Naquela época, não era estranho um Padre ser politico. Padre Cícero entrou na politica depois de 10 anos de proibição do exercício sacerdotal. Como ele escreveu no seu testamento, ele só entrou na politica para impedir que outro candidato, inimigo dos romeiros, tomasse posse de prefeito da nova cidade de Juazeiro. Foi, sobretudo a "guerra de 14", o peso negativo que caiu sobre o padre, como já falei. Só que não foi ele o mandante da operação, mas foi o presidente da Republica, que delegou Floro Bartolomeu para essa missão, usando o Padre e seus romeiros!! O cargo de vice-presidente só foi "figurativo" como o de "deputado federal" depois da morte de seu braço direito, na política, o Dr. Floro Bartolomeu. Padre Cícero usou de sua influencia política em favor dos pobres: pelo menos, é o que constatei, analisando os arquivos. 
Edimar Brígido - Em 2015, nove anos depois do pedido feito pelo bispo Dom Fernando Panico, a Igreja atendeu a solicitação do prelado e reconciliou o padre Cícero com a Igreja. O que levou a Santa Sé a rever seu posicionamento inicial?

Annette Dumoulin - $O$ bom senso e um estudo mais minucioso da vida do Padre Cícero! Além disso, a "teimosia" de milhões de romeiros apontando Padre Cícero como santo! Essa fidelidade impressiona quem observa e constata! "A voz do povo é a voz de Deus"! É o Cardeal Ratzinguer, então Presidente da Sagrada Congregação do Santo Ofício, que fez a proposta de reabrir o processo do Padre Cícero em vista de uma "reabilitação". Esta se transformou em "reconciliação" deixando de lado as punições, e centralizando a questão sobre as "virtudes" humanas e pastorais do Padre Cícero e sua grande influencia no Nordeste e no Brasil.. É claro que o fato do Papa Francisco ser sul-americano deve ter influenciado esse novo posicionamento. Questão de sensibilidade e compreensão da realidade brasileira numa visão menos "canónica" e mais "humana".

Edimar Brígido - Com a reconciliação, não há mais fatores impeditivos para que o "santo popular" do interior do Ceará seja beatificado e, quem sabe um dia, canonizado. A senhora acredita que isso possa acontecer?

Annette Dumoulin - Acredito, sim, mas não sou profeta! De todo jeito, ele já é canonizado pelo povo.

Edimar Brígido - A senhora deixou a universidade na Bélgica, e se dedica há mais de quarenta anos aos romeiros que chegam de todas as partes ao Crato? A senhora se tornou uma devota de padre Cícero?

Annette Dumoulin - Nossas pesquisas em arquivos desde 1974, nossa vivencia continua no meio dos romeiros, nos confirma que Padre Cícero foi um Pastor fiel ao povo que, em sonho, o próprio Jesus the confiou. Alegro-me de colaborar a fazer a verdade sobre o "Padrinho Cícero" que foi tão perseguido, como, alias seus devotos! 
Não me sinto devota dele! Sinto-me muito próxima dele! Converso com ele como a um grande amigo! E reconheço que ele atende com muito carinho aos meus pedidos!

Edimar Brígido - Na sua opinião, o que a história de padre Cícero, sua condenação e posterior reconciliação, pode oferecer de ensinamento para a nossa geração?

Annette Dumoulin - Basta ler a carta do Cardeal Parolin que reconhece que:

No momento em que a Igreja inteira é convidada pelo Papa Francisco a uma atitude de saída, ao encontro das periferias existenciais, a atitude do Padre Cícero em acolher a todos, especialmente aos pobres e sofredores, aconselhando-os e abençoando-os, constitui, sem dúvida, um sinal importante e atual.

Basta ler também a descrição que o Papa Francisco faz sobre o Bom Pastor para convencer-se que o Padre Cícero corresponde bem a essa descrição! Veja:

Ser um pastor na metade do caminho é uma derrota. Um pastor deve ter o coração de Deus, ir até o final, porque não quer que ninguém se perca. $\mathrm{O}$ verdadeiro pastor tem este zelo dentro de si: que ninguém se perca. E por isso não teme sujar as mãos. Não tem medo.

$\mathrm{O}$ verdadeiro Pastor vai aonde deve ir. Arrisca sua vida, arrisca sua fama, arrisca perder sua comodidade, seu status, inclusive perder sua carreira eclesiástica, mas é um bom pastor.

Não tenham medo de que se fale de nós porque vamos ao encontro dos irmãos e irmãs que se afastaram do Senhor.

Esta é também a minha opinião!

Edimar Brígido - Para finalizar nossa entrevista, poderia nos falar um pouco das atividades em andamento e das obras que a senhora publicou a respeito de Padre Cícero?

Annette Dumoulin - Eu tenho 83 anos e minhas atividades em diminuição! 
Ainda sou membro da Pastoral de Romaria no Santuário, acolho os romeiros, faço reuniões com eles (pausa) e cuido do Centro de Psicologia da Religião (em Juazeiro do Norte). Tenho alguns livros sobre padre Cícero: O Padre Cícero por ele mesmo (em colaboração com Therezinha Stella Guimarães), Edições INESP 2015; Em sonho: uma boa conversa entre o romeiro Sebastião e Padre Cícero, Paulinas 2017; Padre Cícero, Santo dos pobres, Santo da Igreja, Paulinas 2017; além de mais alguns artigos. 